\title{
Patients' expectations of private osteopathic care in the UK: a national survey of patients
}

\author{
CM Janine Leach ${ }^{1 *}$, Anne Mandy ${ }^{1}$, Matthew Hankins², Laura M Bottomley ${ }^{1}$, Vinette Cross ${ }^{1}$, Carol A Fawkes ${ }^{1}$, \\ Adam Fiske ${ }^{1}$ and Ann P Moore
}

\begin{abstract}
Background: Patients' expectations of osteopathic care have been little researched. The aim of this study was to quantify the most important expectations of patients in private UK osteopathic practices, and the extent to which those expectations were met or unmet.

Methods: The study involved development and application of a questionnaire about patients' expectations of osteopathic care. The questionnaire drew on an extensive review of the literature and the findings of a prior qualitative study involving focus groups exploring the expectations of osteopathic patients. A questionnaire survey of osteopathic patients in the UK was then conducted. Patients were recruited from a random sample of 800 registered osteopaths in private practice across the UK. Patients were asked to complete the questionnaire which asked about 51 aspects of expectation, and post it to the researchers for analysis.

The main outcome measures were the patients-perceived level of expectation as assessed by the percentage of positive responses for each aspect of expectation, and unmet expectation as computed from the proportion responding that their expectation "did not happen".
\end{abstract}

Results: 1649 sets of patient data were included in the analysis. Thirty five (69\%) of the 51 aspects of expectation were prevalent, with listening, respect and information-giving ranking highest. Only 11 expectations were unmet, the most often unmet were to be made aware that there was a complaints procedure, to find it difficult to pay for osteopathic treatment, and perceiving a lack of communication between the osteopath and their GP.

Conclusions: The findings reflected the complexity of providing osteopathic care and meeting patients' expectations. The results provided a generally positive message about private osteopathic practice. The study identified certain gaps between expectations and delivery of care, which can be used to improve the quality of care. The questionnaire is a resource for future research.

Keywords: Questionnaires, Survey, Expectations, Musculoskeletal manipulations, Osteopathic medicine

\section{Background}

Osteopathic care in the United Kingdom (UK) comprises an important component of the provision of musculoskeletal services [1,2]. In 2001, there were 4442 statutoryregistered osteopaths delivering osteopathic care, based mainly within private practices [3]. While patients' expectations of osteopathic care have been little researched, there is a considerable body of knowledge from other areas of primary and musculoskeletal care.

\footnotetext{
*Correspondence: c.m.j.leach@brighton.ac.uk

${ }^{1}$ Clinical Research centre for Health Professions, University of Brighton, Aldro Building, 49 Darley Road, BN20 7UR, Eastbourne, UK

Full list of author information is available at the end of the article
}

Patients' expectations of their interaction with healthcare are based on cognitive and affective beliefs and values, which evolve in an 'epi-phenomenal' way through dynamic interplay between the therapy and therapist, and the patient's subjective experience of change in symptoms [4-6]. Patients' expectations are culturally modified and vary with age [7-10], gender [11], ethnicity [12], and social factors such as deprivation and unemployment [13]. They also vary with health condition [14]. Musculoskeletal patients often have no prior expectations of treatment, yet they tend to believe that their symptoms have a physical basis and have views about what type of treatment might be appropriate [15]. The formation of expectations and 
perceptions of chiropractic care has been found to be rooted in a lay referral system based upon the successful experience of family and friends, and their recommendation [5].

In the context of primary care, the most important expectation are interpersonal care, followed by competence (symptom relief), involvement in decisions, fast access, and information for self-care [16]. Patients with back pain have specific additional expectations of a clear diagnosis of the cause of pain, explanation of the cause of their problem, a physical examination, and confirmation that their pain is real $[8,14]$. Within complementary therapy, patients also value improved quality of life, avoiding 'toxic' drugs and a holistic approach [17-19]. In private musculoskeletal care, patients act as consumers and manage their care, they make choices of therapy and therapist; they expect value for money and "added extras" in the environment [20], and may bench-mark the quality of the service and professional expertise against NHS primary care [21]. Expectations also influence the outcome of (response to) treatment, including satisfaction with treatment [22-24]. It may be beneficial for clinicians to encourage realistic positive expectations through improved explanation of the problem, and shared decision making [25].

The few studies investigating patients' expectations of osteopathic care have suggested that patients favour the manual nature of manipulation and judge it an appropriate treatment due to its "hands-on" nature [26]. Patients seeking osteopathy or other complementary therapies are likely to have consulted their GP before seeking osteopathic treatment or any form of complementary and alternative medicine (CAM) therapy, and may have received other forms of treatment e.g. physiotherapy, or have tried a selection of CAM therapies before seeking an osteopath [27]; and symptomatic relief was the primary expectation [18]. The desire for an effective and quick resolution to their symptoms was similar whether visiting the osteopath or the GP. Osteopathic studies of patient satisfaction $[21,28,29]$, which is related in part to expectations being met, also emphasise the importance of the interpersonal relationship with the osteopath.

The regulator of the osteopathic profession, the General Osteopathic Council (GOsC), commissioned this research as part of a wider programme of work to enhance knowledge of the attitudes, needs and concerns of the public and patients who seek osteopathic care. This occurred within the context of movement towards patient-centred healthcare within UK health policy [30,31]. The study reported here is the final stage of a mixed methods study, the final report to the funder is publicly available [32]. The initial qualitative stage has been reported [33]. The aim of this stage was to quantify the most important expectations of patients consulting osteopaths, and the extent to which those expectations were met or unmet, in private UK osteopathic practices.

\section{Methods}

The methodology chosen to evaluate the expectations of osteopathic patients was a national patient survey, participants being recruited when consulting osteopaths in private practice, and being invited to complete a questionnaire about their expectations of care.

\section{The questionnaire tool}

There was a lack of standardised or validated measurement tools for expectation [14] although a number of measures have been used in specific contexts or for specific conditions [34-37]. There was also inconsistency between studies in the definition of expectation. For this study, a patient-centred definition was used: expectations about aspects of the consultation as perceived and understood by the patient. This definition is similar to that proposed in a recent study in back pain [14].

An osteopathy-specific questionnaire was developed for this study. A formal development process was adopted [38-42]. The question topics were drawn from a literature review [32] and from focus groups and interviews with osteopathic patients [33]. A semi-structured format was adopted for ease of completion by patients, and to permit statistical analysis [38]. Rating scales were used where possible since these produce more information and variance than other types of response [42]; a 5response scale was selected as being user-friendly and for its statistical properties.

The questionnaire was designed, tested, and piloted in three stages with healthy volunteers and then with osteopathic patients in volunteer practices. More than 70 aspects of expectation were identified initially as candidate questions for the questionnaire. These were refined during the three pilot phases, which involved 45 participants. Fifty-one aspects of expectation were included in the final questionnaire (see Additional file 1), which took about 15 minutes to complete. The final questionnaire comprised four sections:

(1) demographic and personal information;

(2) statements aimed to evaluate which expectations were most prevalent, using Likert rating scales permitting responses from "strongly agree" to "strongly disagree";

(3) statements to evaluate whether or not the expectation had been met (had "actually happened" or not) when visiting the osteopath;

(4) four open-ended questions enabling patients to articulate any other issues they felt were not covered by the questionnaire. 
Factor analysis [43] was undertaken by the study statistician $(\mathrm{MH})$ to determine redundancy and hierarchy of importance of the questions. The factor analysis found that all of the fifty-one questions about expectation contributed information, and none were redundant. The visual appeal and readability of the final version of the questionnaire was improved by use of two font colours (as recommended by www.jisctechdis.ac.uk) and professional graphic design services. The questionnaires were identified by a coded study number comprising a study identifier for the osteopath and sequential codes for participants. There were no hidden codes to identify patients, therefore no reminders could be sent to nonresponders.

\section{Recruitment of patients}

The strategy for recruitment aimed to obtain a large sample of osteopathic patients, recruited via private osteopathic practices, distributed geographically across the whole of the United Kingdom (UK). To optimise diversity of practice type and location, a large (25\%) random sample of osteopaths was used. The sample of osteopaths was drawn with permission from the UK Statutory Register of Osteopaths as published by the General Osteopathic Council in 2009; the sample was stratified to ensure contributions from England, Wales, Scotland, and Northern Ireland. Randomness of sampling from the lists was achieved using integers from a random number generator (www.random.org).

The randomly selected osteopaths were contacted to invite them to assist in recruiting patients for the study, and also to ensure that they were in private practice. NHS practices were excluded because NHS ethical approval had not been sought as there were few such practices and their inclusion could have introduced heterogeneity, making the results less robust [44].

Osteopaths were asked to recruit patients for the survey. Patients were eligible if they were currently receiving treatment, had the capacity to give consent, and were able to complete the questionnaire. The exclusion criteria were: not currently receiving osteopathic treatment, unable to understand the questionnaire, or not having the capacity to consent. Children aged less than 16 years were not eligible. The protocol aimed for a systematic sample of patients: that is, all consecutive, eligible patients attending on given days were invited. To maximise patient compliance [45], osteopaths were asked to start recruitment on a Tuesday morning or as soon as possible thereafter. The instructions to osteopaths stressed the importance of strict adherence to protocol to avoid selection bias. Possible deviation from this protocol was evaluated though a short 'Recruitment form' which osteopaths were asked to complete and return.

\section{Sample size}

The sample size was calculated based on a need for sufficient statistics to undertake some subgroup analysis, for example by age group or region, for both new and returning patients. The minimum sample size for returned questionnaires was set at 1500 in total including at least 500 new patients, which would provide a 95\% confidence interval of $3 \%$ or smaller in estimated proportions overall, or $4 \%$ for new patients [46].

In similar research using recruitment of patients by practitioners [47] the reported rate of participation by practitioners was as low as $33 \%$. The patient response rate was estimated at $50-70 \%$, leading to an overall anticipated response rate of $16-23 \%$. Therefore, in order to realise the required sample size of 1500 patients, each of the random sample of 800 osteopaths was asked to invite 14 patients to participate, comprising at least 4 consecutive new patients and up to 10 consecutive returning patients.

\section{Procedure}

Each of the 800 selected osteopaths was sent a package of study documentation, containing fifteen Participant Questionnaire Packs for patients. Each pack contained a letter of invitation for the patient, the questionnaire, three versions of the Participant Information Sheets designed for adults of various reading ages (15 years and over; 10-14 years; and 5-9 years, respectively). A replypaid addressed envelope was included for return of the completed questionnaire to the researchers. Invited patients were given a pack to take home and read at their leisure, and decide whether or not they wished to complete the questionnaire.

\section{Data entry and analysis}

Completed questionnaires were returned to the Clinical Research Centre and the data were input into an EXCEL spread sheet. Accuracy of entry was assured by checking a sample of 5 (10\%) of each batch of 50 questionnaires: batches yielding more than 1 error in the sample were returned for re-input of all 50 questionnaires. The maximum error rate was therefore 0.0016 (i.e. 1 in 5 sets of 122 data items), less than $0.2 \%$. The numerical and categorical data from the questionnaires were analysed using the Statistical Package for Social Scientists (SPSS) version 16.0. Data quality and missing values were assessed. The responses to the questions with rating scales were assigned numerical values for analysis.

Two statistics were constructed for each aspect of expectation: (1) the prevalence of positive expectation and (2) the prevalence of unmet positive expectation. Positive expectation was defined as agreement with the statement, and was used as it was intuitively understandable and gave almost identical rankings to 
the statistically preferable median score. Unmet expectation was a more complex statistic based on the participant's paired responses from sections $D$ and $E$ of the questionnaire (see Additional file 1) about their expectation and whether or not it they perceived it to have happened. The prevalence of unmet expectation was the percentage of people with positive responses for a given expectation statement who also responded that "it did not happen". An 'unacceptable' level of unmet expectation was defined using concepts from management science of a 'net promoter score' [48]. According to this theory, a business is likely to be successful if the percentage of 'promoters' of the service minus the percentage of 'detractors' is greater than $75 \%$. If patients with unmet expectations are assumed to be detractors, and those whose expectations are met become promoters, the proportion with unmet expectations should not exceed $12.5 \%$.

\section{Ethical approval}

An expert Steering Group was set up by the funder, the General Osteopathic Council, to review project management and progress. Ethics permission was given by the
University of Brighton Faculty of Health Research Ethics and Governance Committee; advice was sought also from the regional NHS Research Ethics Committee. Incentives for patients or telephone reminders to osteopaths to encourage them to participate were not permitted by the ethics committee. If the information on a questionnaire were to suggest very serious misconduct by an osteopath, the researchers would have been obliged to trace the practice concerned and to inform the profession's regulator, the General Osteopathic Council. In the event, no such evidence was found.

\section{Results}

\section{Data collected}

In total, 11,200 questionnaires were distributed and 1,701 completed questionnaires were returned to the researchers, a response rate of $15.2 \%$. Analysis of the identifier codes on the returned questionnaires showed that the questionnaires came from patients attending 259 $(32.4 \%)$ of the 800 osteopaths contacted in the study. The number of patient responses per osteopath ranged from 1 to 14 with a mean of 6.3. Formal comparison of responders and non-responders was carried out by

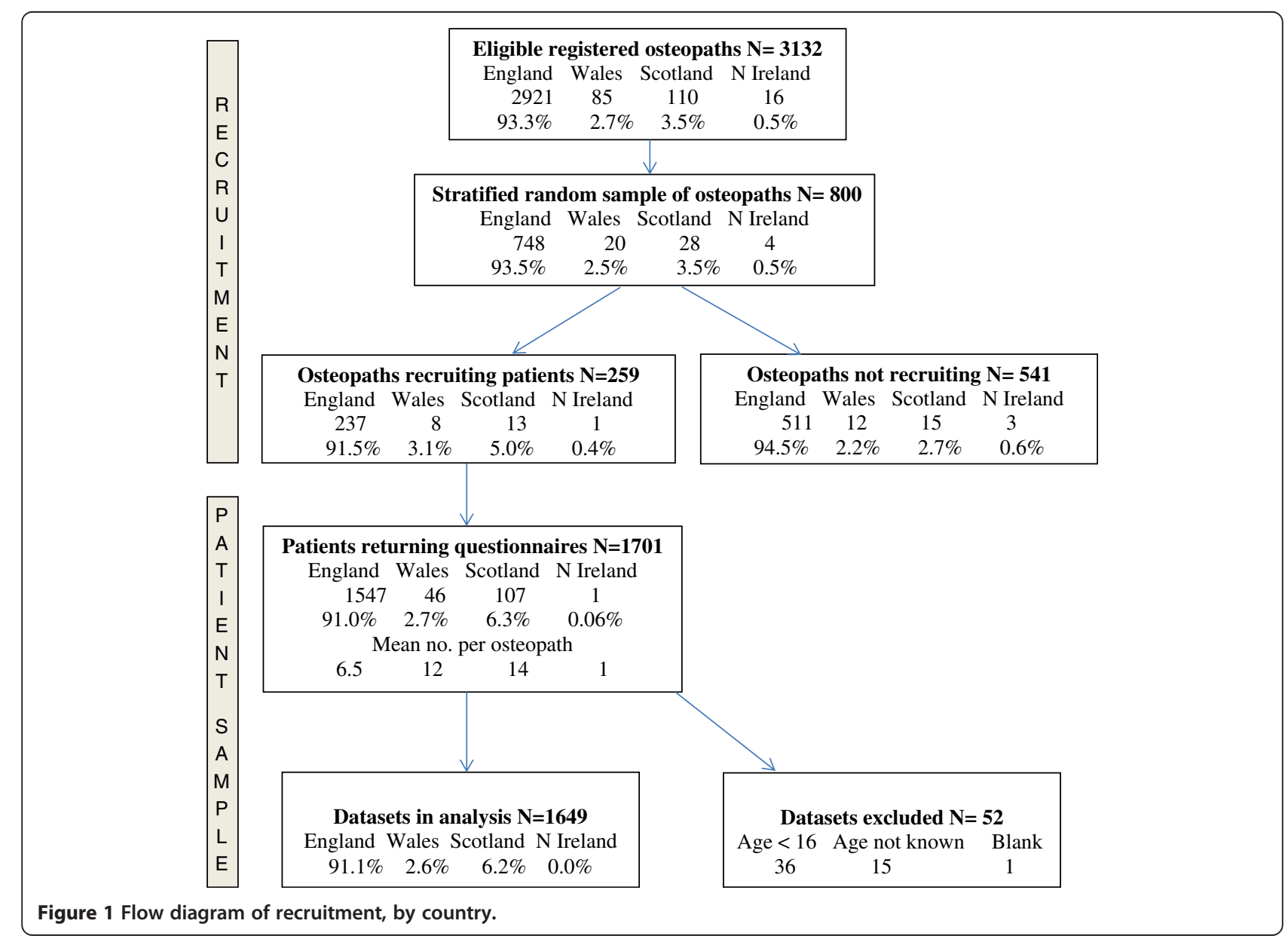


country within the UK, the only information publicly available about participants, as shown in Figure 1, the flow diagram of participant recruitment. Participation and recruitment rates per osteopath were slightly higher in Scotland and lower in Northern Ireland than in the majority region, England. No evidence was found of selection bias in recruitment by osteopaths, using the information on the Recruitment forms returned by 151 (58\%) of participating osteopaths.

\section{Characteristics of respondents}

The characteristics of respondents are shown in Table 1 and are compared to a previous survey [3]. The latter differed in collecting new episodes only, in all age groups, hence the higher proportion of new patients and lower mean age 44.8 (SD +/- 19.1) years compared to 54.0 years $(\mathrm{SD}+/-14.9)$ in this study. The proportion of patients who were new to osteopathy at $17.8 \%$ was similar to that in a survey by the General Osteopathic Council in 2001 [49] which reported 17\% new patients. However both prior surveys found $40 \%$ or more male patients, suggesting that our sample was skewed towards female respondents. Otherwise the characteristics were consistent with prior surveys, with the great majority of patients being white British, and either employed or retired.

Data-checking revealed that responders completed the questionnaires thoroughly, with less than $3 \%$ missing data for most items. After exclusion of a small number of datasets where the patient's age was missing or ineligible, 1649 sets of data were included in the analysis.

Table 1 Characteristics of the 1649 respondents included in the analysis

\begin{tabular}{lccc}
\hline Characteristic & This study & This study & $\begin{array}{c}\text { From Fawkes et al. } \\
\text { 2010 [3] }\end{array}$ \\
& number & $\%$ & $\%$ \\
\hline Gender & & & \\
\hline Male & 499 & 30.3 & 43.0 \\
\hline Female & 1149 & 69.7 & 56.0 \\
\hline Ethnicity & & & \\
\hline White British & 1499 & 90.9 & 85.1 \\
\hline Other & 150 & 9.1 & 14.9 \\
\hline Employment status & & & 45.6 \\
\hline Employed & 655 & 40.3 & 16.5 \\
\hline Self employed & 295 & 17.9 & 19.0 \\
\hline Retired & 523 & 31.7 & 18.9 \\
\hline Other & 166 & 10.1 & 59.0 \\
\hline Naive to osteopathy & & & \\
\hline Yes, new patient & 293 & 17.8 & \\
\hline No, returning patient & 1356 & 82.2 & \\
\hline
\end{tabular}

The general health of respondents was good, only $14.8 \%$ considered their general health was fair or poor, and $11.2 \%$ considered themselves to have a disability. The majority (58.6\%) reported symptoms of moderate severity, though $15.3 \%$ considered their symptoms to be severe. For $51.1 \%$, the duration of symptoms was "years" and for $26.9 \%$ it was days or weeks. Over $52 \%$ had first visited an osteopath 5 or more years ago. Many also had prior experience of physiotherapy $(63.1 \%)$, or chiropractic $(29.8 \%)$. More than $90 \%$ were self-funding their treatment, with $6.9 \%$ funded through insurance and just $0.2 \%$ funded by the NHS.

Over $96 \%$ of patients agreed or strongly agreed that they were satisfied with their treatment, and only $0.3 \%$ (5 patients) were unsatisfied. $4.5 \%$ of respondents added free text describing expectations that they considered had not been met.

One of the fifty-one statements in the main section of the questionnaire was about belief rather than expectation: it was worded "I would be prepared to forgo some luxuries to afford osteopathic treatment". This statement was excluded from the later results which include fifty aspects of expectation. A majority (81.5\%) of respondents agreed that they would be prepared to forgo luxuries; only $40.9 \%$ perceived that this 'did not happen'.

\section{Patients' most prevalent expectations}

'Prevalent' was defined as more than $75 \%$ of respondents responding positively to a statement. Thirty four (68\%) of the 50 aspects of expectation were prevalent, and are shown ranked in Table 2. The corresponding response rates for the 293 (18\%) patients who were new to osteopathy were very similar to those for the study population as a whole.

\section{Unmet expectations}

Most $(24,71 \%)$ of the 34 prevalent expectations were perceived by respondents to be met well, however for 10 (29\%) prevalent expectations the proportion of patients with unmet positive expectations was unacceptable (over $12.5 \%$ ) or borderline, as shown in Table 3. Five of these prevalent expectations had rather high levels (more than $20 \%$ ) of unmet positive expectations. In general, new patients had similar though slightly higher levels of unmet expectation than respondents as a whole. However, the percentage of unmet expectations was substantially higher in new patients in relation to three issues, marked by asterisks in Table 3: being asked about the effects of previous treatment, provided with pre-treatment information about what to expect, and being given advice on prevention.

Table 4 provides an overview of the prevalence of expectation ('customer demand') tabulated against the level 
Table 2 The 34 most prevalent aspects of expectations of osteopathic care, ranked by \% positive responses What do you expect when you go to an osteopath?

\begin{tabular}{|c|c|}
\hline I expect to be able to ask questions & $99.8 \%$ \\
\hline I expect the osteopath to listen to me & $99.1 \%$ \\
\hline I expect to be treated with respect. & $98.8 \%$ \\
\hline I expect to be given a clear explanation of my problem that I understand & $98.7 \%$ \\
\hline I expect the osteopath to only treat one patient at one time & $97.9 \%$ \\
\hline I expect the osteopath to take a detailed account of my clinical history. & $97.6 \%$ \\
\hline I expect the clinic environment to be hygienic and professional looking & $97.5 \%$ \\
\hline I expect the osteopath to make me feel at ease & $97.5 \%$ \\
\hline I expect to be given advice about how to manage my symptoms myself & $96.4 \%$ \\
\hline I expect my questions to be answered to my satisfaction & $96.2 \%$ \\
\hline I expect to be reassured that the information that I am asked to provide will be kept confidential & $96.1 \%$ \\
\hline I expect to be given advice on how to prevent the same problem happening again & $94.3 \%$ \\
\hline I expect my osteopathic treatment to be value for money & $93.5 \%$ \\
\hline I expect to be given a choice of appointment times & $92.8 \%$ \\
\hline I expect the practice to display evidence of the osteopaths professional qualifications & $92.7 \%$ \\
\hline I expect the osteopath to monitor my reaction to his/her treatment & $92.3 \%$ \\
\hline I expect to be given information about the risks and side effects of treatment & $90.7 \%$ \\
\hline I expect to see the same osteopath each time & $90.5 \%$ \\
\hline I expect to be able to phone the osteopath for advice if I needed & $89.7 \%$ \\
\hline I expect the osteopath to identify my problem area with her/his hands. & $89.5 \%$ \\
\hline I expect the osteopath to be sympathetic and caring & $88.3 \%$ \\
\hline I expect to be given an explanation of what the treatment will involve before it is given & $88.3 \%$ \\
\hline I expect to be given information about the benefits of treatment & $86.8 \%$ \\
\hline I expect the consultation to last at least thirty minutes & $86.6 \%$ \\
\hline I expect the waiting area to be comfortable and relaxing & $84.1 \%$ \\
\hline I expect to be involved in making decisions about my treatment & $84.0 \%$ \\
\hline I expect the osteopath to refer me elsewhere if my symptoms are not improving & $83.9 \%$ \\
\hline I expect to be given activities or exercises to do at home & $80.8 \%$ \\
\hline I expect the practice to make provision for people with disabilities & $80.1 \%$ \\
\hline I expect to be asked about effects of previous treatment & $80.0 \%$ \\
\hline $\begin{array}{l}\text { If I am not satisfied with any part of my treatment I would expect to be given information about how to } \\
\text { make a formal complaint }\end{array}$ & $79.6 \%$ \\
\hline I would expect there to be communication between my osteopath and GP if necessary & $78.0 \%$ \\
\hline Before my first treatment I expect to be given information about what will happen during treatment. & $77.3 \%$ \\
\hline
\end{tabular}

of unmet expectation ('service delivery'). Borderline categories of five percentage points have been created, $2.5 \%$ either side of the cut-off levels of $75 \%$ for expectation being "prevalent", and $12.5 \%$ for unmet expectation being an acceptable level of customer service, respectively. The table emphasises that 28 of the 50 (56\%) of all expectations were met well, and 21 of those 28 (75\%) were prevalent expectations. Six expectations (12\%) were on the borderline of unacceptable service delivery, three of these being prevalent expectations. Sixteen expectations (32\%) were poorly met, of which nine were prevalent expectations. The less prevalent unmet expectations should not be over-looked; they included the use of consent forms and provision of gowns for modesty. Among the patients who did expect these items, a high proportion found their expectation unmet.

Three of the 50 expectations related to aspects of care that are likely to be undesirable, such as pain and discomfort, or other patients being treated at the same time. For these, unmet expectations could be viewed as beneficial. These undesirable aspects are shown in bold in Table 4.

The nine unmet prevalent expectations were mapped against five broad conceptual themes describing patient expectations which had emerged in the first qualitative 
Table 3 The ten prevalent expectations that were unmet overall (fourteen unmet for new patients) ranked by \% with unmet positive expectations

\begin{tabular}{|c|c|c|}
\hline \multirow[b]{2}{*}{ What actually happened during your visits to the osteopath? } & \multicolumn{2}{|c|}{$\%$ with unmet expectations } \\
\hline & All respondents & New patients only \\
\hline I was made aware that there is a complaints procedure should I need to use it & 65.63 & 70.8 \\
\hline There was communication between my osteopath and GP about my problem & 33.91 & 34.68 \\
\hline I was informed of the risks and side effects of the treatment & 22.98 & 23.85 \\
\hline There was access for people with disability & 22.46 & 25.48 \\
\hline The osteopath was able to refer me elsewhere when my symptoms did not improve & 21.92 & 20.75 \\
\hline I was asked about the effects of previous treatment & 17.23 & $36.26^{*}$ \\
\hline The osteopath assured me that my details were kept confidential & 17.02 & 21.09 \\
\hline I was given the opportunity to receive advice from the osteopath over the telephone & 15.78 & 15.12 \\
\hline Before my first appointment I was given information about what would happen during treatment. & 14.8 & $25.23^{*}$ \\
\hline I was given advice on how to prevent the problem happening again & 12.5 & $20.9^{*}$ \\
\hline The osteopath did not treat other patients at the same time as me & & 13.83 \\
\hline I was given activities and exercises to do at home & & 15.06 \\
\hline I did see evidence of the osteopaths' qualifications & & 14.74 \\
\hline I was given information about the benefits of treatment & & 12.79 \\
\hline
\end{tabular}

phase of the study [33]. There were no unmet expectations that mapped onto the 'therapeutic process' or 'individual agency' themes. Expecting to be made aware that there was a complaints procedure, disability access and telephone advice all fall within the 'customer experience' theme; a perceived lack of communication between their osteopath and their GP, options of referral on, and being asked about the effects of previous treatment fall within 'professional expertise'; and assurance of confidentiality and information about risks and side effects mapped onto the' interpersonal relationship' theme.

\section{Discussion}

The study has provided the first statistically robust profile of the expectations of osteopathic patients, with a reasonable sample size (1,649 in the analysis). Osteopathic patients' expectations are very complex and encompass at least 50 different aspects of care. More than $75 \%$ of the respondents agreed that they did expect $34(68 \%)$ of the 50 expectations statements'. In the 'top ten' expectations, there was an emphasis on open exchange of information; and overall they represent an interesting mix of service, conduct, therapeutic relationship, professional expertise, information-giving, and ethical aspects of care.

Most (71\%) of the 34 prevalent expectations were met to a good or acceptable level, providing a positive message for the osteopathic profession. Five expectations were particularly poorly met and highlight areas where service quality could be improved. The unmet expectations may reflect the fact that osteopathy as a profession is in the process of moving from the marginalised position of a CAM profession [46] into more mainstream healthcare, for example being recommended within NICE guidelines [2]. Patients are also demanding a higher level of customer service [16]. There were some areas where perhaps more investigation is needed. For example, attitudes to being provided with a towel or gown for modesty, or the need to sign a consent form.

The study results were highly consistent with existing evidence, including a systematic review of patient expectations of treatment for back pain [8], and with previous osteopathic studies [21,26,28].

This study has many implications for practice in osteopathy and possibly in other CAM professions. Osteopaths may need to make certain aspects of their professional decisions more explicit, for example how and when they communicate with the appropriate wider network of health professionals in their area, including the patient's GP; and how and when they conduct their process of triage at the first appointment, with a view to onward referral if required. Osteopaths can also enhance trust and improve the interpersonal relationship with patients by providing more information about risks and side effects of treatment, and provide reassurance of confidentiality, since most patients expect these. New patients may require more pre-treatment information, be asked to sign a consent form, and offered a towel or gown for modesty.

The main limitation of the study was the possibility of selection bias due to the low response rate. The low participation rate (32\%) of the randomly selected osteopaths, despite an active strategy to raise awareness and motivation, was disappointing but not atypical of other studies relying for recruitment from a 
Table 4 Summary of expectations by prevalence (\% positive agreement) and the degree to which they were met (\% positive expectations that did not happen)*

\begin{tabular}{|c|c|c|c|}
\hline $\begin{array}{l}\text { Expectations (\%) } \\
\text { Meeting positive expectations (\%) }\end{array}$ & Prevalent expectations (>77.5\%) & $\begin{array}{l}\text { Borderline expectations } \\
\quad(72.5-77.5 \%)\end{array}$ & $\begin{array}{l}\text { Less prevalent expectations } \\
\qquad(<72.5 \%)\end{array}$ \\
\hline \multirow{13}{*}{$\begin{array}{l}\text { Expectations met well or adequately } \\
(15-100 \%)\end{array}$} & 21 & 2 & 5 \\
\hline & Evidence of qualifications & Clear diagnosis & Gentle/ vigorous treatment \\
\hline & Information on benefits & Privacy for undressing & Symptoms improved \\
\hline & Involvement in decisions & & Pain-free treatment \\
\hline & Self-management advice & & \\
\hline & $\begin{array}{l}\text { Explanation of treatment and of cause of } \\
\text { problem }\end{array}$ & & \\
\hline & Comfortable waiting area & & \\
\hline & Choice of appointment time and osteopath & & \\
\hline & Value for money & & \\
\hline & Case History taken & & \\
\hline & Manual examination & & \\
\hline & Empathy, respect and listening & & \\
\hline & Able to ask questions & & \\
\hline \multirow[t]{4}{*}{ Borderline (10-14.9\%) } & 3 & 2 & 1 \\
\hline & Prevention advice & $\begin{array}{l}\text { Discomfort after } \\
\text { treatment }\end{array}$ & $\begin{array}{l}\text { Initial estimate of treatments } \\
\text { required }\end{array}$ \\
\hline & Other patients treated at same time & Pre-visit information & \\
\hline & Home exercises advice & & \\
\hline \multirow[t]{8}{*}{ Poorly met $(<10 \%)$} & 8 & 0 & 8 \\
\hline & $\begin{array}{l}\text { Informed of complaints procedure; risks; } \\
\text { confidentiality }\end{array}$ & & $\begin{array}{l}\text { Negotiate cost Gown or towel } \\
\text { provided }\end{array}$ \\
\hline & Communication with GP & & Electrotherapy \\
\hline & Disability access & & Gender of osteopath \\
\hline & Referral on & & Able to have chaperone \\
\hline & Asked about prior treatment effects & & Consent form \\
\hline & Telephone advice & & Worse after treatment \\
\hline & & & Initial prognosis \\
\hline
\end{tabular}

"Bold items in Table 4 denote undesirable rather than desirable aspects of care.

random sample of practitioners with no incentives [47]. The response rate among patients was higher at around $48 \%$ (based on the assumption that only $32 \%$ of osteopaths invited patients to participate, so at most 3600 questionnaires were distributed) providing less opportunity for bias. The representativeness of the sample was supported by data from similar previous studies, although participation was slightly skewed by country and gender. Communications from 31 osteopaths who refused to participate included several lengthy letters and anecdotal reasons for nonparticipation suggested a lack of research awareness and concerns about the value of this research and research in general. The patient respondents were rather homogeneous and appeared typical of the profile of private osteopathic patients nationally [3] in tending to be well educated, white Caucasian, and either employed or retired. Homogeneity increases the robustness of the findings with respect to the research question, but limits their generalisability to populations with different ethnicity or socially less advantaged groups.

The analysis treated all responses as independent data points, but since there were varying numbers from different practices it is possible that the results were skewed by a clustering effect. We did not adjust for this because of the wide range of responses from different practices.

Expectations are not static, they evolve during the course of treatment [50,51] hence the timing of measurements may be important. In this study, posttreatment expectations were collected and appeared to differ surprisingly little between new and returning patients. It would be useful to compare these data 
with pre-treatment expectations and also to compare expectations in patients with chronic and acute symptoms.

The questionnaire was new and, although un-validated, was thoroughly piloted; it performed well, being completed consistently by respondents with few gaps and no obvious ambiguities in the framing of questions. Only a small number of additional expectations were elicited in the open questions, suggesting that most relevant aspects had been covered. Future minor amendments to be considered include more direct questions about immediate or substantial impact on symptoms, and possible re-framing of the questions on pain and on financial costs. The questionnaire has proved its value and will provide a useful resource for the future.

\section{Conclusions}

This study was the first to directly measure the expectations of osteopathic patients and the extent to which patients' expectations were met or unmet. In private osteopathic practices, patients' expectations appeared to be generally met well.

The results provided guidance for patients about what it is reasonable to expect when they seek osteopathic care. The study has identified certain gaps between expectations and the delivery of care, which can be used to improve the quality of care provided by osteopaths, through the regulator via standards, through educators via training, and through the professional body which supports osteopathic practices to improve service delivery.

The questionnaire is now a resource for future research, including surveys in other settings such as the training clinics in osteopathic education institutions, in NHS services or overseas. Further survey research is recommended to confirm the current findings and to evaluate expectations within more diverse populations of osteopathic patients. Slight modification to the questionnaire is recommended to take account of the new aspects identified. Further exploratory research is needed to gain understanding of patients' expectations about aspects such as communication between the osteopath and the GP, the consent process and arrangements for undressing.

\section{Additional file}

Additional file 1: The study questionnaire.

\footnotetext{
Abbreviations

CAM: Complementary and alternative medicine; GP: General practitioner; NHS: National Health Service (UK); NICE: National institute for health and clinical excellence (UK)
}

\section{Competing interests}

The funder of the study was the General Osteopathic Council whose remit as regulator of the profession is to safeguard the interests of patients; their interest was to assure that the study was conducted well and provided accurate information for patients. Three of the authors (Leach, Fawkes, Fiske) were osteopaths in private practice.

\section{Authors' contributions}

CMJL was principal investigator conducting the study, AM lead the design and testing of the questionnaire and advised on analysis of the survey, $\mathrm{MH}$ was the statistician who conducted the analysis, LMB and AF created the participant databases and conducted data quality checking, VC carried out the focus groups and identified the topics for the questionnaire, CAF was the main reviewer of the literature under-pinning the study, APM advised on all stages of the study and analysed the focus group data. All authors read and approved the final manuscript.

\section{Acknowledgements}

We are grateful to the General Osteopathic Council (GOsC) for funding the study and for making available an electronic extract from the statutory register of osteopaths; to members of the expert Steering Group for their advice on scientific, ethical and professional aspects of the study; to all the osteopathic practices and patients that participated in the study, and to members of staff at GOsC and the British Osteopathic Association who assisted with the study.

\section{Source of funding}

The General Osteopathic Council, UK.

\section{Author details}

${ }^{1}$ Clinical Research centre for Health Professions, University of Brighton, Aldro Building, 49 Darley Road, BN20 7UR, Eastbourne, UK. Faculty of Health Sciences, University of Southampton, Southampton, Highfield SO17 1BJ, UK.

Received: 23 January 2013 Accepted: 22 May 2013

Published: 31 May 2013

\section{References}

1. Department of Health: The musculoskeletal services framework. London: DH Publications; 2006.

2. National Institute for Health and Clinical Excellence: Low Back Pain: early management of persistent non-specific low back pain. NICE Clinical guideline CG88. London: NICE; 2009.

3. Fawkes C, Leach J, Mathias S, Moore AP: Standardised data collection within osteopathic practice in the UK: development and first use of a tool to profile osteopathic care in 2009; 2010. http://www.osteopathy. org.uk/uploads/standardised_data_collection_finalreport_24062010. pdf: General Osteopathic Council.

4. Thompson AG, Sunol R: Expectations as determinants of patient satisfaction: concepts, theory and evidence. Int J Qual Health Care 1995, 7(2):127-141.

5. Yardley L, Sharples K, Beech S, Lewith G: Developing a dynamic model of treatment perceptions. J Health Psychol 2001, 6:269.

6. Georgy EE, Carr EC, Breen AC: Met or matched expectations: what accounts for a successful back pain consultation in primary care? Health Expect 2013, 16:143-54.

7. Goldstein MS, Morgenstern H, Hurwitz EL, Yu F: The impact of treatment confidence on pain and related disability among patients with low-back pain: results from the University of California, Los Angeles, low-back pain study. Spine J 2002, 2(6):391-399. discussion 399-401.

8. Verbeek J, Sengers MJ, Riemens L, Haafkens J: Patient expectations of treatment for back pain: a systematic review of qualitative and quantitative studies. Spine 2004, 29(20):2309-2318.

9. Rutishauser C, Esslinger A, Bond L, Sennhauser FH: Consultations with adolescents: the gap between their expectations and their experiences. Acta Paediatr 2003, 92(11):1322-1326.

10. Tsao JC, Meldrum M, Bursch B, Jacob MC, Kim SC, Zeltzer LK: Treatment expectations for CAM interventions in pediatric chronic pain patients and their parents. Evid Based Complement Alternat Med 2005, 2(4):521-527. 
11. Vieder JN, Krafchick MA, Kovach AC, Galluzzi KE: Physician-patient interaction: what do elders want? J Am Osteopath Assoc 2002, 102(2):73-78.

12. Mead N, Roland M: Understanding why some ethnic minority patients evaluate medical care more negatively than white patients: a cross sectional analysis of a routine patient survey in English general practices. BMJ 2009, 339:b3450.

13. Moffett JA, Underwood MR, Gardiner ED: Socioeconomic status predicts functional disability in patients participating in a back pain trial. Disabil Rehabil 2009, 31(10):783-790.

14. Georgy EE, Carr EC, Breen AC: Back pain management in primary care: patients' and doctors' expectations. Qual Prim Care 2009, 17(6):405-413.

15. May S: Patients' attitudes and beliefs about back pain and its management after physiotherapy for low back pain. Physiother Res Int 2007, 12(3):126-135.

16. Coulter $\mathrm{A}$ : What do patients and the public want from primary care? BMJ 2005, 331(7526):1199-1201.

17. Bishop F, Yardley L, Lewith G: A systematic review of beliefs involved in the use of complentary and alternative medicine. Journal of Health Psychology 2007, 12(6):851-867.

18. Richardson J: What patients expect from complementary therapy: a qualitative study. Am J Public Health 2004, 94(6):1049-1053.

19. Sirois FM, Gick ML: An investigation of the health beliefs and motivations of complementary medicine clients. Soc Sci Med 2002, 55(6):1025-1037.

20. Bishop FL, Barlow F, Coghlan B, Lee P, Lewith GT: Patients as healthcare consumers in the public and private sectors: a qualitative study of acupuncture in the UK. BMC Health Serv Res 2011, 11:129.

21. Strutt $R$, Shaw $Q$, Leach J: Patients' perceptions and satisfaction with treatment in a UK osteopathic training clinic. Man Ther 2008, 13:456-467.

22. Linde K, Witt CM, Streng A, Weidenhammer W, Wagenpfeil S, Brinkhaus B, Willich SN, Melchart D: The impact of patient expectations on outcomes in four randomized controlled trials of acupuncture in patients with chronic pain. Pain 2007, 128(3):264-271.

23. Myers SS, Phillips RS, Davis RB, Cherkin DC, Legedza A, Kaptchuk TJ, Hrbek A, Buring JE, Post D, Connelly MT, et al: Patient expectations as predictors of outcome in patients with acute low back pain. J Gen Intern Med 2008, 23(2):148-153

24. Rubinstein SM, Knol DL, Leboeuf-Yde C, de Koekkoek TE, Pfeifle CE, van Tulder MW: Predictors of a favorable outcome in patients treated by chiropractors for neck pain. Spine (Phila Pa 1976) 2008, 33(13):1451-1458.

25. Fassaert $T$, van Dulmen $S$, Schellevis $F$, van der Jagt $L$, Bensing J: Raising positive expectations helps patients with minor ailments: A cross-sectional study. BMC Fam Pract 2008, 9:38.

26. Westmoreland $\mathrm{L}$, Williams NH, Wilkinson C, Wood F, Westmoreland A: Should your GP be an osteopath? Patients' views of an osteopathy clinic based in primary care. Complement Ther Med 2007, 15(2):121-127.

27. Vincent $C$, Furnham A: Why do patients turn to complementary medicine? An empirical study. Br J Clin Psychol 1996, 35(Pt 1):37-48.

28. Licciardone J, Gamber R, Cardarelli K: Patient satisfaction and clinical outcomes associated with osteopathic manipulative treatment. J Am Osteopath Assoc 2002, 102(1):13-20.

29. Pincus $T$, Vogel $S$, Savage $R$, et al: Patients' satisfaction with osteopathic and GP management of low back pain in the same surgery. Comple Therap Med 2000, 8:180-186.

30. LoD D: High quality care for all: NHS next stage review final report. London: Department of Health; 2008.

31. Department of Health: White paper 'equity and excellence: liberating the NHS'. TheStationery Office; 2010. http://www.dh.gov.uk/en/Healthcare/ LiberatingtheNHS/index.htm.

32. Leach CMJ, Cross V, Fawkes C, Mandy A, Hankins M, Fiske A, Bottomley L, Moore AP: Investigating osteopathic patients' expectations of osteopathic care:the OPEn project. Full Reseach Report. London; 2011. GOsC http://www.osteopathy. org.uk/resources/research/Osteopathic-Patient-Expectations-OPEn-study/.

33. Cross V, Leach CMJ, Fawkes CA, Moore AP: Exploring patients' expectations of osteopathic care: a qualitative study. Health Expect, in press 2013.

34. Deyo R, Diehl A: Patient satisfaction with medical care for low back pain. Spine (Phila Pa 1976) 1986, 11:28-30.

35. Salmon P, Quine J: Patients' intentions in primary care: Measurement and preliminary investigation. Psychol Health 1989, 3:103-110.
36. Kravitz R, Callahan E, Azari R, et al: Assessing patients' expectations in ambulatory medical practice. J Gen Intern Med 1997, 12:67-72.

37. Peck BM, Asch DA, Goold SD, Roter DL, Ubel PA, Mclntyre LM, Abbott KH, Hoff JA, Koropchak CM, Tulsky JA: Measuring patient expectations: does the instrument affect satisfaction or expectations? Medical Care 2001, 39(1):100-108.

38. Boynton PM, Greenhalgh T: Selecting, designing and developing your questionnaire. BMJ 2004, 328:1321-1315.

39. Fowler F: Survey research methods. Thousand Oaks, CA: Sage Publications; 2009.

40. Fink A, Kosecoff J: How to conduct surveys. A step by step guide. 2nd edition. Thousand Oaks, CA: Sage Publications; 1998.

41. Sapsford R: Survey research. London: Sage publications; 1999

42. Punch KF: Survey research. London: Sage Publications; 2003.

43. Gorsuch L: Factor analysis. Abingdon, Oxford: Routledge; 1998.

44. Staniszewska S, Ahmed L: The concepts of expectation and satisfaction: do they capture the way patients evaluate their care? J Adv Nurs 1999, 29(2):364-372

45. Hoddinott SN, Bass MJ: The dillman total design survey method. Can Fam Physician 1986, 32:2366-2368.

46. Stone J: Risk, regulation and the growing marginalisation of CAM. Comple Therap Clinic Prac 2010, 16(1):1-2.

47. MacPherson $H$, Thomas K: Short term reactions to acupuncture-a cross-sectional survey of patient reports. Acupunc med: j Brit Med Acupunc Soc 2005, 23(3):112-120.

48. Reichheld F: The one number you need to grow. Harvard Business Review: Harvard Business Review; 2003.

49. General Osteopathic Council: Snapshot survey 2001. London: GOSC; 2001. http:// www.osteopathy.org.uk/uploads/survey2snapshot_survery_results_2001.pdf.

50. Yardley L, Sharples K, Beech S, Lewith G: Developing a dynamic model of treatment perceptions. J Health Psychol 2001, 6(3):269-282

51. Parsons S, Harding G, Breen A, Foster N, Pincus T, Vogel S, Underwood M: Will shared decision making between patients with chronic musculoskeletal pain and physiotherapists, osteopaths and chiropractors improve patient care? Fam Pract 2012, 29(2):203-212.

doi:10.1186/1472-6882-13-122

Cite this article as: Leach et al.: Patients' expectations of private osteopathic care in the UK: a national survey of patients. BMC Complementary and Alternative Medicine 2013 13:122.

\section{Submit your next manuscript to BioMed Central and take full advantage of:}

- Convenient online submission

- Thorough peer review

- No space constraints or color figure charges

- Immediate publication on acceptance

- Inclusion in PubMed, CAS, Scopus and Google Scholar

- Research which is freely available for redistribution

Submit your manuscript at www.biomedcentral.com/submit
C Biomed Central 